\title{
An analysis of using flipped learning in Higher Education: 'How flipping difficult can it be?'
}

\author{
Bramley, Gareth ${ }^{\mathrm{a}}$
}

${ }^{a}$ University Teacher, University of Sheffield, School of Law

\begin{abstract}
This paper aims to provide a discussion of how to implement flipped learning as a teaching method in Higher Education.

A study of using flipped learning was carried out within the context of a module on the undergraduate law degree programme at the University of Sheffield. Prior to this study, flipped learning had not been attempted on any undergraduate law module at the University. Students undertaking the module were asked to complete a survey, and quantitative comments were collated. These results will be presented and analysed in this paper. This paper also draws on academic literature to compare perspectives of incorporating this method of teaching into the HE curriculum.

This paper summarises the reasons for carrying out the study, together with the key findings from this study. The key conclusions of the paper focus primarily on the benefits of incorporating flipped learning into teaching with the central benefits being deeper learning for students, and increased engagement in the subject matter. The paper also comments on some of the challenges of this teaching method - the central challenges being the need for consistency and clear signposting, together with a large investment of time by staff in implementing such a teaching method.
\end{abstract}




\section{Introduction}

The theme of this paper is the incorporation of 'flipped learning' within Higher Education teaching. Flipped learning is often credited to the work of Bergmann and Sams (Bergmann, J; Samms, A. 2012), and can be described as follows:

"In the flipped classroom, instructors prerecord lectures and post them online for students to watch on their own so that class time can be dedicated to student-centred learning activites, like problem based learning and inquiry oriented strategies" (McLaughlin, $\mathrm{J}$ et al. 2014)

Bergmann and Sams have often been described as the 'pioneers' of flipped learning, and started the 'Flipped Learning Network' in 2012 to promote the use of flipped learning in Higher Education (Hamdan and McKnight. 2012). The concept of making pre-recorded content is not a new concept, and has been used successfully by many e.g. The Khan Academy. However, Bergmann and Samms and many others have sought to focus on the pedagogical benefits of flipped learning, in particular the importance of "in class time" (Little, C. 2015).

There is relatively little academic literature on the use of flipped learning within the UK, when compared with the large number of studies conducted in the USA. This is particularly true of teaching within Law. However, bodies such as the Higher Education Authority (HEA) are now seeking to publicise and encourage the use of flipped learning within the UK. The study summarized in this paper was undertaken to highlight the use of flipped learning, particularly within the sphere of Law, and to encourage other courses and institutions to follow the flipped learning example.

This paper focuses on the implementation of a flipped learning methodology, within a module entitled 'Commercial law - sale of goods' on the undergraduate LLB law degree programme at the University of Sheffield. The module chosen is an elective final year module, and has approximately 100 students enrolled (out of a total cohort of approximately 250 students). The module is a very popular choice for students on the LLB law degree each year, and has been run successfully for over 10 years. However, prior to this study, flipped learning has not been incorporated at all into the module. Indeed, there is currently no other module on the LLB law degree that incorporates full flipped learning (as defined above). Therefore, an additional aim of this paper is to encourage others within the School of Law to incorporate flipped learning into their teaching. 


\section{Methods}

The 'Commercial law-sale of goods' module offered as an elective module within the LLB law degree, previously consisted of $20 \times 1$ hour lectures, and $6 \times 2$ hour seminars, over a teaching semester (1 October to 18 December approx.).

To undertake a study into flipped learning, it was decided that the traditional taught lectures be recorded as screencasts (that is, Powerpoint slides with an audio commentary) and embedded within the Virtual Learning Environment ('VLE') available to students. Each module on the LLB law degree programme has a separate area on the VLE, and various content can be uploaded for access by those students enrolled on the particular module. The 20 lecture bookings were kept, but were renamed as 'interactive lectures'. The 6, 2 hour, taught seminars were also maintained.

Prior to the commencement of the module in October 2015, the lecturers on this module scripted and recorded approximately 20 screencasts (using Powerpoint to display and order through the slides, and Articulate software to record the audio commentary).

In the first week of the module, the module convenors held an introductory face-to-face lecture. Given that the cohort had never enrolled on a full flipped learning module before, detailed instructions were given to the students as to how to approach the learning and preparation for the work on the module.

Specifically, the students were told that the pre-recorded screencasts were released on a weekly basis to students, for watching prior to two interactive lecture slots each week. The screencasts covered the essential points previously delivered via a 'traditional' lecture, with the aim that a 1 hour lecture could be summarised within a 15 minute screencast. The screencasts could be then replayed by students as many times as desired. On average, there were between one and three screencasts for the students to watch each week (with the full module taking place over a 12 week period).

In the face-to-face interactive lectures, the lecture started with a short 10 minute summary of what the students had focused on in the pre-recorded screencasts. The students were then given a number of different activities to undertake, with the focus on 'active', problembased learning (Bergmann and Sams. 2012). These activities included both whole cohort and small group tasks. Following time for consideration of these tasks, the lecturers engaged the students in an open dialogue about the answers to such tasks.

Following the interactive lecture, the students attended separate small group (20 students approx.) seminars, where they worked through different problem-based questions and essay-style questions in smaller groups of 3-4 students. The seminar tutors then engaged the students in an open dialogue, building upon what had been discussed in the interactive lectures and focusing ahead to the assessment for the module. 


\section{Results and discussion}

The students undertaking this module were asked to complete a short survey on the flipped learning that they had received. This survey was embedded within the VLE, and the results were collated. Out of a cohort of 100 students, 38 students completed the survey.

Given that there are a number of different ways that the pre-recorded element of flipped learning can be delivered, the students were asked as to their preference of format. Figure 1 shows clearly that the students would not have preferred to view the pre-recorded screencasts as a video lecture, and that the screencast format (slides, with audio commentary) was preferable.

\section{Would you have preferred the screencasts to be in video format, with the lecturer visible?}

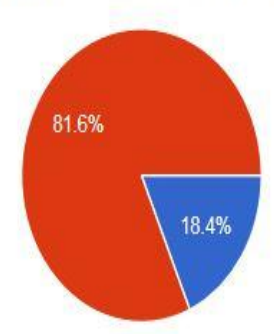

$$
\begin{array}{rrr}
\text { Yes } & 7 & 18.4 \% \\
\text { No } & \mathbf{3 1} & 81.6 \%
\end{array}
$$

Fig. 1 -feedback on format of screencasts

Figure 2 shows that the majority of the students that answered the survey, felt that they had sufficient time to watch the screencasts and carry out any other preliminary reading prior to the lectures.

\section{Did you have enough time to watch the screencasts and carry out the reading before the lectures?}

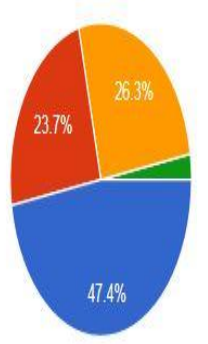

$$
\begin{array}{rrrr}
\qquad \text { I had sufficient time to properly prepare } & 18 & 47.4 \% \\
\text { It was a push, but I managed to prepare - the screencasts could be shorter } & 9 & 23.7 \% \\
\text { I did not have enough time to complete the reading and watch the screencast } & 10 & 26.3 \% \\
\text { I did not understand what was required of me in advance of the lectures } & 1 & 2.6 \%
\end{array}
$$

Fig 2. - feedback on sustainability of preparation for interactive lectures 
Figure 3 shows that the students felt they were prepared for the interactive lectures, and that they were able to actively take part in the activities in the lectures as a result.

\section{Did you feel that you were able to take part in, and be prepared for, the activities in the lectures?}

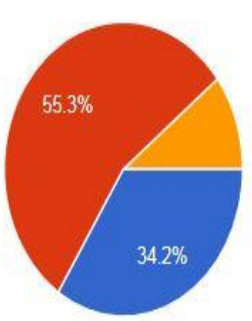

$\begin{array}{rrr}\text { Strongly agree } & \mathbf{1 3} & 34.2 \% \\ \text { Agree } & \mathbf{2 1} & 55.3 \% \\ \text { To some extent } & \mathbf{4} & 10.5 \% \\ \text { Disagree } & \mathbf{0} & \mathbf{0} \%\end{array}$

Fig. 3 -feedback on the level of preparation for the interactive lectures

Figure 4 shows that most of the students who answered the survey felt engaged with flipped learning. It is acknowledged that quite a few of the students felt that it took time to get used to the format of the module. This was anticipated when this project was first envisaged, particularly as students had not engaged in any form of flipped learning prior to this module.

\section{Choose a statement that you feel applies most to you}

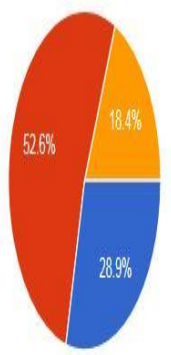

The lectures were productive and f felt much more prepared and engaged $1128.9 \%$ This module took a while to get used to butl can see the benefits for my learing and l feel engaged $2052.0 \%$ I prefer lectures and seminars, without interaction in lectures and without preparation before lectures. Iengage more with those methods $\quad 7 \quad 18.4 \%$ I did not engage with this form of teaching and didn't feel any more prepared I

Fig. 4-feedback on the format of the module

Figure 5 contains two pie-charts, which relate to the screencasts themselves, and how students reacted to their inclusion in the teaching content. The first chart shows that, overwhelmingly, the students found that the screencasts were very helpul in helping them prepare for lectures and seminars. The second chart shows that the vast majority of students who were surveyed found the screencasts interesting, and informative for their learning. 
Did you find the screencasts were helpful in preparing you for lectures and seminars?

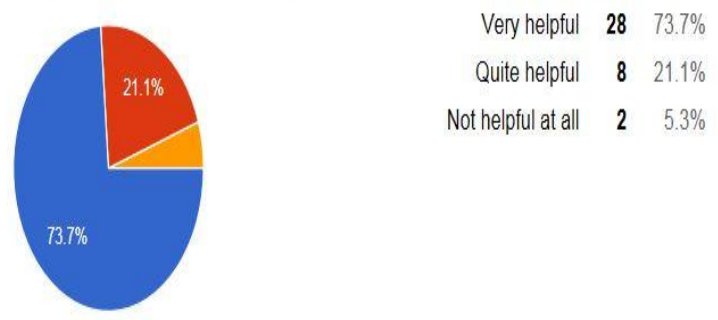

What did you think of the screencast content?

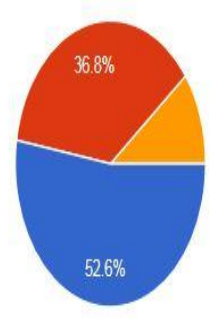

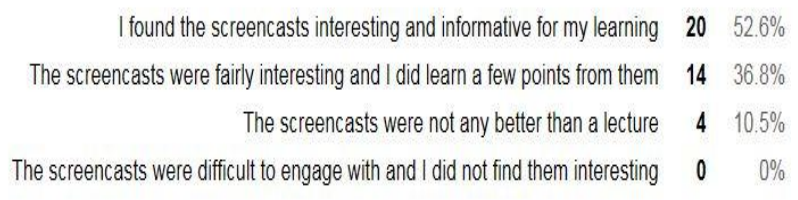

Fig. 5 -feedback on the screencast content

From the results of the survey completed by the students, a few clear conclusions can be drawn. Firstly, it is clear that the students who answered the survey found the screencasts interesting and informative.

The literature in this area sets out that engagement is improved in particular by the fact that the students have the ability to re-listen to the screencasts as many times as desirable (Little, C. 2015). It would be useful to ask the cohort in future years how many times they viewed the screencasts, or what their favourite features of the screencasts were.

It has been recognized that, with any delivery of teaching content, learning needs to be manageable. For instance, with traditional lectures, it has been show that students' attention delicles after the first 10 minutes and students only remember about $20 \%$ of the material during an hour of teaching (McLaughlin, J. 2014).

Secondly, it is clear that the students were able to use the screencasts to assist them in their preparation, when they attended lectures and seminars. Again, this reflects what others have commented on in relation to flipped learning. Flipped learning allows for the in-class time to focus on higher order cognitive skills (Little, C. 2015) i.e. it allows students to apply the higher levels of Bloom's Taxonomy (Bloom, 1956), such as the skills of analysis and evaluation, rather than not progressing past comprehension and knowledge. Therefore, 
deeper learning is achieved as a result (Orsmond, 2004), and the ability of students to achieve a wider range of learning skills is encouraged (Bergmann and Sams. 2012)

Thirdly, it is clear from the results of the survey that the students felt they had sufficient time to prepare for lectures and seminars. This paper submits that this in itself is linked to engagement - better engagement from the students allows for the students to learn, put their learning into context and 'grow as a learner' (Fox, 1983).

From the survey undertaken, we plan to run the model of flipped learning on this module again in the Autumn 2016 semester. We will survey the students again, with the following additional aims:

(i) A response from all students was not achieved in this study and therefore there may well be students who did not find the method of teaching so favourable. We will try to encourage more engagement in the survey next time.

(ii) On the survey questions, the students were not asked about how they found the interactive lecture content itself, and additionally how this influenced their performance in seminars. A perceived benefit of flipped learning is that it allows for student-led learning, rather than teacher led learning. It would have been useful to try and gauge student opinion on this point, to more fully evaluate an improvement in student learning. Therefore, these questions will be added to the next survey

(iii) Furthermore, the survey does not analyse any final results achieved by the students in their summative assessment, and how these results compared and contrasted with previous years results. It is submitted that this is not the only important factor to consider when making changes to learning and teaching, but it would have been a useful comparator.

The staff teaching on this course also highlighted some challenges with introducing flipped learning in this way. As commented on above, introducing this method involves a large investment of time initially, particularly in the recording of screencasts and re-design of lectures. This is something acknowledged by the 'pioneers' of flipped learning themselves (Bergmann and Sams, 2012).

Also, the students require clear support from the start and a clear setting of student expectations is essential - if students do not see the benefit of this method of learning from the start, or do not understand how to approach such a method of teaching, then the success of flipped learning can be affected. At times, staff did perceive some students to be a bit confused about how much time to spend preparing for interactive lectures, and what benefits this hoped to achieve in respect of their learning. In future years, this could be 
more explicitly set out from the start, perhaps referring to factors such as student engagement and deeper learning.

\section{Conclusion}

This paper concludes that flipped learning can be a very meaningful, fulfilling and successful method of learning and teaching. As has been set out, flipped learning as a concept has been championed by many as a much better pedagogical device than the traditional teacher-led lecture and seminar format.

It has been reflected in the study undertaken and the results received from students undertaking this mode of teaching, that flipped learning can allow for greater preparation for, and engagement in taught sessions, more time for focusing on activities involving deeper learning (such as analysis and evaluation) in class time, and more time to focus on student-centred learning (allowing students to grow as a learner, rather than simply seek to gain comprehension and knowledge without further developlemt).

However, it has also been acknowledged that incorporating flipped learning can be challenging. It requires a lot of time initially to incorporate a fully flipped experience, particularly on a module with a larger cohort of students. In addition, it requires a clear message provided to the students from the start and throughout, about what is expected of them as learners and what benefits can result.

\section{References}

Bloom, B. S. (1956). Taxonomy of Educational Objectives. New York: David McKay.

Fox, D (1983). Personal theories of teaching. Studies in Higher Education. Volume 8, No.2

Orsmond, P (2004). Self and Peer Assessment - Guidance on Practice in the Biosciences. Higher Education Authority.

Bergmann, J; Sams, A (2012). Flip your classroom: Reach every student in every class every day. International society for technology in education

Hamdan, N; Knight, P (2013). The flipped learning model: a white paper based on the literature review titled a review of flipped learning.

McLaughlin, J et al (2014). The Flipped classroom: a course redesign to foster learning and engagement in a health professional school. Academic Medicine, Vol. 89. No. 2

Little, C. (2015). The flipped classroom in further education: literature review and case study. Research in Post Compulsory Education. Vol 20, No. 3 